\title{
Comorbid Conditions in Patients With Metastatic Colorectal Cancer
}

\author{
Alex Z Fu ${ }^{\mathrm{a}, \mathrm{d}}$, Zhongyun Zhao ${ }^{\mathrm{b}}$, Sue Gao ${ }^{\mathrm{b}}$, Beth Barber ${ }^{\mathrm{b}}$, Gordon G Liu ${ }^{\mathrm{c}}$
}

\begin{abstract}
Background: Patients with metastatic colorectal cancer (mCRC) often have other medical conditions that may impact treatment decisions, prognoses and quality of care. We aimed to assess co-existing medical conditions in the $\mathrm{mCRC}$ patient population. This retrospective cohort study used linked medical and pharmacy claims data from two US-based Medstat MarketScan claims databases and identified patients with newly diagnosed mCRC between January 2005 and June 2008.
\end{abstract}

Methods: Patient data were analyzed for comorbid conditions and medication use in the year prior to diagnosis of mCRC. Univariate analyses were conducted to compare the comorbid conditions between patients aged $\geq 65$ and $<65$ years old. In total, 12648 patients aged $\geq 18$ years were identified. The study was evenly populated by gender and age above and below 65 , and most patients had a primary diagnosis of colon cancer $(70.1 \%)$.

Results: The most prevalent comorbidity was cardiovascular disease (CVD) $(55.7 \%$ of patients) including hypertension $(40.8 \%)$, cardiac dysrhythmia $(14.2 \%)$, coronary artery disease $(13.5 \%)$, congestive heart failure $(7.2 \%)$ and arterial and venous thromboembolism (6.2\% and $4.6 \%$, respectively). Most comorbidities were significantly more prevalent in patients $\geq 65$

Manuscript accepted for publication September 23, 2011

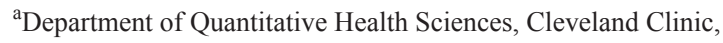
Cleveland, Ohio, USA

${ }^{\mathrm{b}}$ Amgen Inc, One Amgen Center Drive, Thousand Oaks, CA 91320-1799, USA

${ }^{\mathrm{c}}$ Guanghua School of Management, Peking University, Beijing, China ${ }^{\mathrm{d}}$ Corresponding author: Alex Z Fu, Department of Quantitative Health Sciences, Cleveland Clinic, 9500 Euclid Avenue/JJN3-01 Cleveland, OH 44195 USA. Email: fuz@ccf.org

doi:10.4021/wjon370e years of age, particularly with respect to CVD $(67.9 \%$ versus $42.5 \%$, respectively; $\mathrm{P}<0.0001)$. Additionally, nearly half $(49.7 \%)$ of the patients received antihypertensive agents and many patients were prescribed more than one class of medications prior to $\mathrm{mCRC}$ diagnosis.

Conclusions: Comorbid medical conditions, particularly CVDs, are common in patients with mCRC, which could increase the complexity of patient management. This should be a consideration integral to the selection of the most appropriate treatment for individual patients.

Keywords: Cardiovascular disease; Comorbidities; Metastatic colorectal cancer; Patient management

\section{Introduction}

Colorectal cancer (CRC) is the second leading cause of death from cancer in the USA, with 146970 new cases and 49 920 deaths estimated in 2008 [1]. Of newly diagnosed CRC patients, $15 \%$ to $25 \%$ have metastatic disease at diagnosis, while disease recurrence and the development of distant metastases occur in up to $50 \%$ of all patients initially diagnosed at earlier disease stages [2]. Similarly in Europe, CRC is also the second most common form of cancer and the second most common cause of death from cancer [3].

Overall survival for patients with metastatic CRC $(\mathrm{mCRC})$ has increased dramatically in the last 20 years largely due to advances in systemic therapy (newer chemotherapies and the introduction of biologic agents) [4]. Additionally, the treatment has become more personalized for patients with mCRC. For example, the benefits of the epidermal growth factor receptor (EGFR) antagonists cetuximab and panitumumab are limited to patients with wildtype KRAS (the proto-oncogene Kirsten ras sarcoma virus) mCRC. Although there are significant gains in clinical benefit, biologics are associated with recognized adverse events (AEs) that may limit their beneficial effects in some patients [5-7]. Gastrointestinal perforations, fistulae, haemorrhage, hypertension and arterial thromboembolism are some of the serious AEs associated with bevacizumab [8,9], while the 
EGFR antagonist class is associated with hypomagnesaemia, infusion reactions and skin toxicities [7, 10-14].

The incorporation of the three different biologic treatments into the $\mathrm{mCRC}$ armamentarium offers a degree of flexibility regarding the most appropriate choice of biologics. Consideration of AE risk plays a role in treatment selection to ensure an acceptable risk-benefit profile. Preexisting comorbidities in patients with mCRC may also play a role in order to avoid toxicity issues [15]. Taking age and comorbidities into consideration as part of treatment selection is, therefore, not uncommon in the management of cancer. For example, in advanced lung cancer, both age and comorbidity play an important role in treatment decisions [16]. There are, however, limited existing data regarding the extent of comorbid conditions in patients with mCRC.

The aim of this study was to comprehensively assess coexisting medical conditions in the $\mathrm{mCRC}$ patient population in clinical practice.

\section{Methods}

\section{Source data}

This was a retrospective cohort study using longitudinal, integrated medical and pharmacy claims data from two Medstat MarketScan claims databases: the Commercial Claims and Encounters database and the Medicare Supplemental and Coordination of Benefits database. These databases include fully de-identified patient-level, paid and adjudicated medical and pharmacy claims histories of 30 million covered lives belonging to 12 national and regional health plans in the USA. The databases are representative of the US national commercially-insured population and those who have both Medicare coverage and supplemental employer-sponsored coverage. They capture the full continuum of care in all settings including physician office visits, hospital stays and outpatient pharmacy claims.

\section{Sample selection and data extraction}

Data on patients with newly diagnosed $\mathrm{mCRC}$ between January 2005 and June 2008 were extracted from the databases using the International Classification of Disease 9th Revision, Clinical Modification (ICD-9-CM) diagnosis codes for CRC (153.x [excluding 153.5], 154.0, 154.1, 154.8) and distant metastasis $(196.0,196.1,196.3,196.5,197 . x$ [excluding 197.5], 198, 199.0). The index date was defined as the date of the initial mCRC diagnosis. Only patients aged $\geq 18$ years at the index date and with at least 1-year continuous medical and drug benefit coverage prior to the index date, and with a first identified distant metastasis diagnosis date no more than 30 days after the first identified CRC diagnosis date were included in the data set. Demographic and clinical character- istics reported included age, gender, geographical location, type of insurance plan, cancer type (colon versus rectal) and location of metastases.

Comprehensive comorbidities were examined in this study including cardiovascular disease (CVD); existing wounds (bone fractures, wound-healing complications, open wounds); history of bleeding/haemorrhage; digestive system disorders; diabetes mellitus; diseases of the blood; diseases of the skin; respiratory system disorders; smoking history; renal failure; and obesity. Using ICD-9 diagnosis codes, comorbid medical conditions were examined during the 1-year prior to the index date, and in the case of traumatic conditions (e.g., bone fracture and open wound) data during 30 days prior to the index date were assessed. Additionally, data on medications taken during the 1 year prior to the index date were extracted using prescription information.

\section{Statistical analysis}

Patient demographics and comorbid conditions defined by ICD-9 codes prior to $\mathrm{mCRC}$ diagnosis were summarized descriptively for the overall patient population using the 1-year pre-index period data. Similarly, medications received prior to $\mathrm{mCRC}$ diagnosis were summarized descriptively. Univariate analyses were conducted to compare the comorbid conditions between patients aged $\geq 65$ and $<65$ years old. Chi-square tests were used to compare proportions of comorbidities between patients aged $\geq 65$ and $<65$ years old.

\section{Results}

Based on the selection criteria, 12648 patients were eligible for inclusion in the analysis of comorbid conditions and medication use in the year prior to diagnosis of mCRC. The study population had $54 \%$ of men, and just over half were aged $>65$ years $(52 \%)$. The majority of the study population had a primary diagnosis of colon cancer (70\%) as opposed to rectal cancer, and the mean age of the study population (standard deviation) was 66.3 (13.1) years (Table 1).

The most frequent comorbidities in the overall population are shown in Table 2, which indicates that CVDs were most commonly reported (55.7\%), followed by digestive system disorders $(29 \%)$, a history of bleeding $(28.3 \%)$ and diabetes mellitus (19.1\%). Among the patients with comorbid CVD, hypertension was the most common condition $(40.8 \%)$ followed by heart disease $(28 \%)$, including cardiac dysrhythmia (14.2\%), coronary artery disease (13.5\%), congestive heart failure $(7.2 \%)$, ischemic heart disease $(6.2 \%)$, arterial thromboembolism (ATE) $(6.2 \%)$, and venous thromboembolism (VTE) (4.6\%).

Elderly patients $\geq 65$ years of age had a significantly higher prevalence of CVDs compared with younger patients (67.9\% versus $42.5 \%$ respectively; $\mathrm{P}<0.0001$; Table 2 ). 
Table 1. Characteristics of Study Population

\begin{tabular}{|c|c|c|}
\hline Variable & $\mathbf{n}$ & Mean or percentage \\
\hline Age, mean $\pm \mathrm{SD}$, year & 12648 & $66.3 \pm 13.1$ \\
\hline $18 \leq$ Age $<40$ & 240 & $1.9 \%$ \\
\hline $40 \leq$ Age $<50$ & 1012 & $8.0 \%$ \\
\hline $50 \leq$ Age $<65$ & 4819 & $38.1 \%$ \\
\hline Age $\geq 65$ & 6577 & $52.0 \%$ \\
\hline Gender: male (versus female) & 6855 & $54.2 \%$ \\
\hline \multicolumn{3}{|l|}{ Geographic region } \\
\hline Northeast & 1189 & $9.4 \%$ \\
\hline North Central & 4364 & $34.5 \%$ \\
\hline South & 4490 & $35.5 \%$ \\
\hline West & 2568 & $20.3 \%$ \\
\hline Unknown & 38 & $0.3 \%$ \\
\hline \multicolumn{3}{|l|}{ Urban versus rural residence } \\
\hline Urban & 10245 & $81.0 \%$ \\
\hline Rural & 2353 & $18.6 \%$ \\
\hline Missing & 51 & $0.4 \%$ \\
\hline \multicolumn{3}{|l|}{ Insurance plan type } \\
\hline Comprehensive & 4174 & $33.0 \%$ \\
\hline HMO & 2125 & $16.8 \%$ \\
\hline PPO & 5059 & $40.0 \%$ \\
\hline POS-non-capitated & 734 & $5.8 \%$ \\
\hline Other/unknown & 557 & $4.4 \%$ \\
\hline Cancer type: colon (versus rectum) & 8866 & $70.1 \%$ \\
\hline \multicolumn{3}{|l|}{ Location of metastasis } \\
\hline Liver & 5084 & $40.2 \%$ \\
\hline Lung & 1796 & $14.2 \%$ \\
\hline Bone & 696 & $5.5 \%$ \\
\hline Brain & 379 & $3.0 \%$ \\
\hline Others & 4693 & $37.1 \%$ \\
\hline
\end{tabular}

SD: standard deviation; HMO: Health Maintenance Organization; PPO: Preferred Provider Organization; POS: Point of Service plan.

Similarly, individual heart-related comorbidities were significantly more prevalent in those aged $\geq 65$ years $(39.5 \%$ versus $15.6 \%$; $<<0.0001$ ) with the exception of acute myocarditis (Table 2). The prevalence of diabetes mellitus was also significantly higher among the older age group $(21.6 \%$ versus $16.5 \% ; \mathrm{P}<0.0001$ ), as were comorbidities relating to diseases of the skin and subcutaneous tissue, renal failure and insufficiency, and respiratory diseases $(\mathrm{P}<0.0001)$. Obesity and history of bleeding were the only two comorbidities with a significantly higher prevalence in those aged $<65$ years of age $(\mathrm{P}<0.0001)$.

Medications received prior to diagnosis are shown in Table 3. The most common medications were antibiotics (61.7\%), and antihypertensive agents (49.7\%). The percentages in Table 3 cumulatively suggest that many patients were prescribed more than one class of medications prior to mCRC diagnosis.

\section{Discussion}

The findings of this retrospective cohort study indicate that comorbid medical conditions are common in patients with mCRC. CVDs are the most prevalent comorbidities, and are significantly more prevalent in patients over 65 years old, affecting more than two-thirds of this group. As might be anticipated based on the comorbidities identified, this study also showed that patients with $\mathrm{mCRC}$ are frequently treated with non-CRC-related medications, mostly for CVDs and gastrointestinal diseases. The high frequency of CVD as a comorbidity in this study population might be anticipated given that more than half of patients were $>65$ years of age. In addition to hypertension, the most frequently reported CVDs were heart diseases (including cardiac dysrhythmia and congestive heart failure), stroke, ATE and VTE.

Although data on pre-existing comorbidities in mCRC 


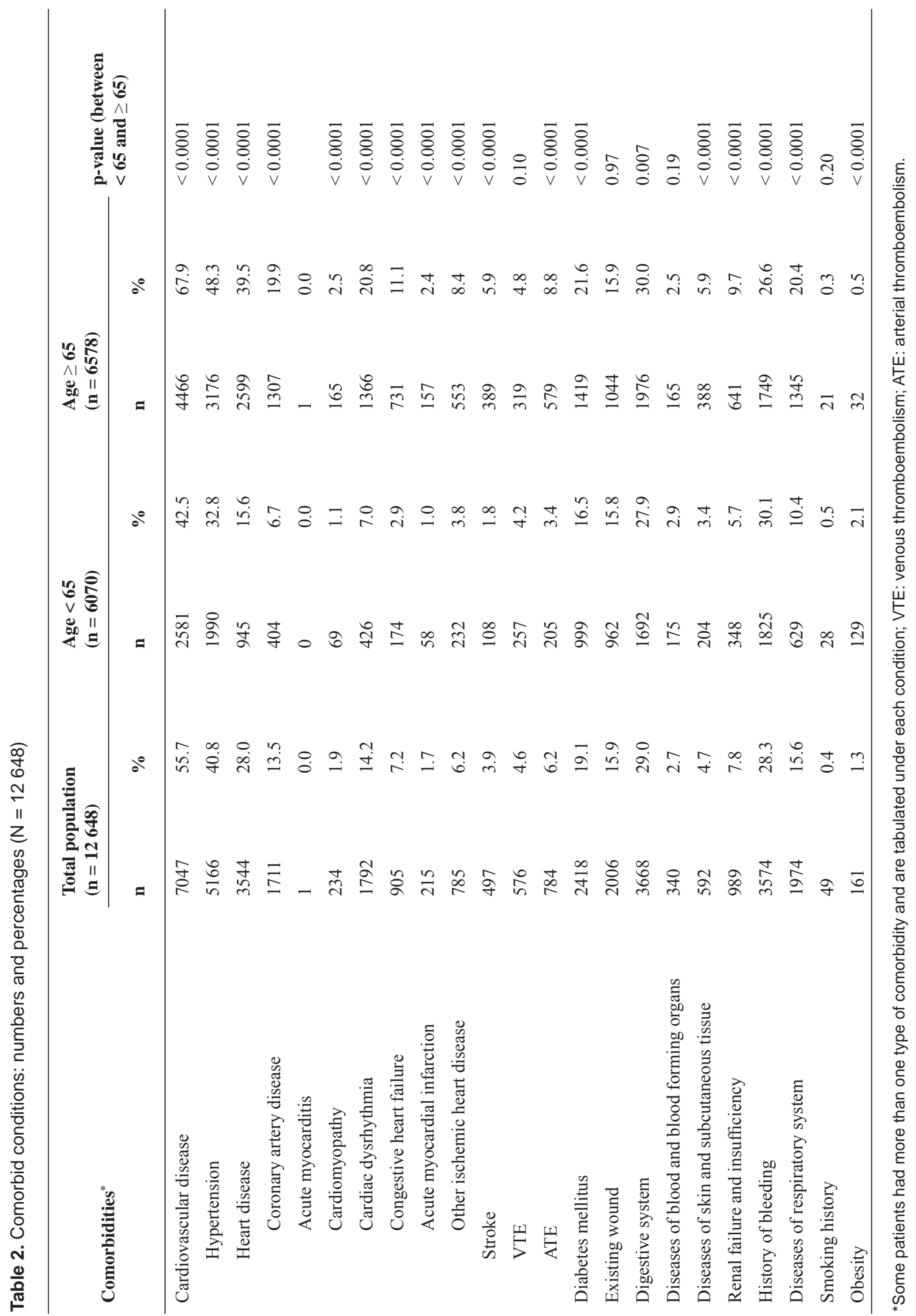


Table 3. Medications Received Prior to Diagnosis of $\mathrm{mCRC}(\mathrm{N}=12648)$

\begin{tabular}{lll}
\hline Variable & Number & Percentage (\%) \\
\hline Cardiac drugs & & \\
\multicolumn{1}{c}{ Antihypertensives } & 6286 & 49.7 \\
Other cardiac drugs & 4123 & 32.6 \\
$\quad$ Anticoagulant & 1492 & 11.8 \\
$\quad$ Antiplatelet drugs & 734 & 5.8 \\
$\quad$ Vasodilating drugs & 734 & 5.8 \\
Antibiotics & 7804 & 61.7 \\
Antihyperlipidemics & 3719 & 29.4 \\
Diuretics & 3036 & 24.0 \\
NSAIDs & 2188 & 17.3 \\
Antiallergic drugs & 1986 & 15.7 \\
Antidiabetic drugs & 1935 & 15.3 \\
Antidiarrhoea drugs & 1075 & 8.5 \\
Anticonvulsants & 974 & 7.7 \\
H2 antagonists & 696 & 5.5 \\
Antiulcer & 696 & 5.5 \\
\hline
\end{tabular}

NSAIDs: non-steroidal anti-inflammatory drugs.

are limited, some information is available on patients with $\mathrm{CRC}$ of any stage in whom the most common comorbidities are reported to be similar to those presented here. Yancik et al [17] reported hypertension, serious heart conditions, gastrointestinal problems, arthritis and chronic obstructive pulmonary disease as the most prominent comorbid conditions in patients with colon cancer of any stage and these findings have been corroborated by later studies [18-20]. Our finding showed that many co-existing conditions, including the majority of CVD comorbidities, diabetes mellitus, diseases of the skin and subcutaneous tissue, renal failure and insufficiency, and respiratory diseases, occurred more frequently in patients aged $>65$ years is also supported by data from the colon cancer setting [17].

Some of the comorbidities identified in our study are likely to be of particular importance to consider. For example, comorbid conditions relating to a history of bleeding and/or existing wounds were identified in $28.3 \%$ and $15.9 \%$ of patients in this cohort study, respectively. Wound-healing complications have also been linked with treatment regimens that include bevacizumab $[8,21]$. This may be particularly important in patients who are eligible for metastasectomy. In consideration of these factors, a delay in elective surgery of up to 8 weeks after completion of bevacizumab, and a similar delay in restarting after liver surgery, is recommended [22].

Our findings also show that VTE and ATE occurred in $4.6 \%$ and $6.2 \%$ of patients with mCRC, respectively. A recent meta-analysis evaluating the use of bevacizumab in nearly 8000 patients with a variety of advanced solid tumours from 15 randomized controlled trials (RCTs) concluded that the drug was significantly associated with an increased risk of developing VTE $(\mathrm{P}<0.001)$ compared with controls, an effect independent of dose [23]. An earlier meta-analysis found an association between bevacizumab and ATE ( $\mathrm{P}=$ 0.031) using data from five RCTs [24].

Comorbid diseases of the skin and subcutaneous tissue together were identified in $4.7 \%$ of all patients, increasing in frequency in the elderly sub-population. This is of relevance to the management of $\mathrm{mCRC}$ as skin toxicities are frequently reported in clinical trials of cetuximab and panitumumab [7, $11,14,25]$.

Our study is associated with a number of limitations. The comorbidities identified in this study were based on healthcare service use data, thus comorbid conditions that did not trigger healthcare service use in the year prior to $\mathrm{mCRC}$ diagnosis were not captured. Also, the prevalence rates for conditions of smoking history and obesity identified in this study were very low. This is likely due to under-reporting of 
these two conditions in claims databases. Finally, our results are reflective of the population studied and may not be extrapolated to the mCRC population in general.

In conclusion, comorbid conditions were frequently observed in patients prior to a diagnosis of mCRC. The presence of these comorbidities increases the complexity of managing the patient's condition. In current treatment guidelines, the presence of comorbidities is included as a factor that should be considered in the choice of chemotherapy for mCRC [15]. Given that, in addition to chemotherapy, there is now a choice of biologic agents for $\mathrm{mCRC}$, each with a well-defined and distinct AE profile, consideration of comorbid conditions should now be integral to the selection of all components of the treatment regimen for individual patients with $\mathrm{mCRC}$.

\section{Acknowledgements}

This study was funded by Amgen Inc. Medical writing assistance was provided by ApotheCom ScopeMedical Ltd, funded by Amgen Inc. Alex Z Fu and Gordon G Liu received funding from Amgen Inc to perform the analyses reported in this manuscript. Zhongyun Zhao, Sue Gao and Beth Barber are employees of Amgen Inc.

\section{References}

1. Jemal A, Siegel R, Ward E, Hao Y, Xu J, Thun MJ. Cancer statistics, 2009. CA Cancer J Clin. 2009;59(4):225249.

2. Kindler HL, Shulman KL. Metastatic colorectal cancer. Curr Treat Options Oncol. 2001;2(6):459-471.

3. Ferlay J, Autier P, Boniol M, Heanue M, Colombet M, Boyle P. Estimates of the cancer incidence and mortality in Europe in 2006. Ann Oncol. 2007;18(3):581-592.

4. Kopetz S, Chang GJ, Overman MJ, Eng C, Sargent DJ, Larson DW, Grothey A, et al. Improved survival in metastatic colorectal cancer is associated with adoption of hepatic resection and improved chemotherapy. J Clin Oncol. 2009;27(22):3677-3683.

5. Giantonio BJ, Catalano PJ, Meropol NJ, O’Dwyer PJ, Mitchell EP, Alberts SR, Schwartz MA, et al. Bevacizumab in combination with oxaliplatin, fluorouracil, and leucovorin (FOLFOX4) for previously treated metastatic colorectal cancer: results from the Eastern Cooperative Oncology Group Study E3200. J Clin Oncol. 2007;25(12):1539-1544.

6. Jonker DJ, O'Callaghan CJ, Karapetis CS, Zalcberg JR, Tu D, Au HJ, Berry SR, et al. Cetuximab for the treatment of colorectal cancer. N Engl J Med. 2007;357(20):20402048.
7. Van Cutsem E, Peeters M, Siena S, Humblet Y, Hendlisz A, Neyns B, Canon JL, et al. Open-label phase III trial of panitumumab plus best supportive care compared with best supportive care alone in patients with chemotherapy-refractory metastatic colorectal cancer. J Clin Oncol. 2007;25(13):1658-1664.

8. Roche. Avastin ${ }^{\circledR}$ US prescribing information. 2010

9. Saltz LB, Clarke S, Diaz-Rubio E, Scheithauer W, Figer A, Wong R, Koski S, et al. Bevacizumab in combination with oxaliplatin-based chemotherapy as first-line therapy in metastatic colorectal cancer: a randomized phase III study. J Clin Oncol. 2008;26(12):2013-2019.

10. ImClone Systems Inc. and Bristol-Myers Squibb Company. Erbitux ${ }^{\circledR}$ US prescribing information. 2010

11. Van Cutsem E, Kohne CH, Hitre E, Zaluski J, Chang Chien CR, Makhson A, D'Haens G, et al. Cetuximab and chemotherapy as initial treatment for metastatic colorectal cancer. N Engl J Med. 2009;360(14):14081417.

12. Amgen Inc. Vectibix ${ }^{\circledR}$ US prescribing information. 2010

13. Peeters M, Price TJ, Cervantes A, Sobrero AF, Ducreux M, Hotko Y, Andre T, et al. Randomized phase III study of panitumumab with fluorouracil, leucovorin, and irinotecan (FOLFIRI) compared with FOLFIRI alone as second-line treatment in patients with metastatic colorectal cancer. J Clin Oncol. 2010;28(31):4706-4713.

14. Douillard JY, Siena S, Cassidy J, Tabernero J, Burkes R, Barugel M, Humblet Y, et al. Randomized, phase III trial of panitumumab with infusional fluorouracil, leucovorin, and oxaliplatin (FOLFOX4) versus FOLFOX4 alone as first-line treatment in patients with previously untreated metastatic colorectal cancer: the PRIME study. J Clin Oncol. 2010;28(31):4697-4705.

15. National Comprehensive Cancer Network (NCCN) Clinical Practice Guidelines in Oncology: Colon Cancer, 2010a (V.3.2010) [http://www.nccn.org/professionals/physician_gls/PDF/colon.pdf]. Last accessed August 2010

16. Blanco JA, Toste IS, Alvarez RF, Cuadrado GR, Gonzalvez AM, Martin IJ. Age, comorbidity, treatment decision and prognosis in lung cancer. Age Ageing. 2008;37(6):715-718.

17. Yancik R, Wesley MN, Ries LA, Havlik RJ, Long S, Edwards BK, Yates JW. Comorbidity and age as predictors of risk for early mortality of male and female colon carcinoma patients: a population-based study. Cancer. 1998;82(11):2123-2134.

18. Gross CP, Guo Z, McAvay GJ, Allore HG, Young M, Tinetti ME. Multimorbidity and survival in older persons with colorectal cancer. J Am Geriatr Soc. 2006;54(12):1898-1904.

19. Janssen-Heijnen ML, Maas HA, Houterman S, Lemmens VE, Rutten HJ, Coebergh JW. Comorbidity in older surgical cancer patients: influence on patient care 
and outcome. Eur J Cancer. 2007;43(15):2179-2193.

20. Shack LG, Rachet B, Williams EM, Northover JM, Coleman MP. Does the timing of comorbidity affect colorectal cancer survival? A population based study. Postgrad Med J. 2010;86(1012):73-78.

21. Hochster HS, Hart LL, Ramanathan RK, Childs BH, Hainsworth JD, Cohn AL, Wong L, et al. Safety and efficacy of oxaliplatin and fluoropyrimidine regimens with or without bevacizumab as first-line treatment of metastatic colorectal cancer: results of the TREE Study. J Clin Oncol. 2008;26(21):3523-3529.

22. Ellis LM, Curley SA, Grothey A. Surgical resection after downsizing of colorectal liver metastasis in the era of bevacizumab. J Clin Oncol. 2005;23(22):4853-4855.
23. Nalluri SR, Chu D, Keresztes R, Zhu X, Wu S. Risk of venous thromboembolism with the angiogenesis inhibitor bevacizumab in cancer patients: a meta-analysis. JAMA. 2008;300(19):2277-2285.

24. Scappaticci FA, Skillings JR, Holden SN, Gerber HP, Miller K, Kabbinavar F, Bergsland E, et al. Arterial thromboembolic events in patients with metastatic carcinoma treated with chemotherapy and bevacizumab. J Natl Cancer Inst. 2007;99(16):1232-1239.

25. Bokemeyer C, Bondarenko I, Makhson A, Hartmann JT, Aparicio J, de Braud F, Donea S, et al. Fluorouracil, leucovorin, and oxaliplatin with and without cetuximab in the first-line treatment of metastatic colorectal cancer. J Clin Oncol. 2009;27(5):663-671. 